J. Lake Sci. (湖泊科学), 2014, 26(5): 799-806

http://www. jlakes. org. E-mail : jlakes@niglas.ac.cn

(C) 2014 by Journal of Lake Sciences

\title{
富营养化湖泊水体中藻蓝蛋白提取方法的对比
}

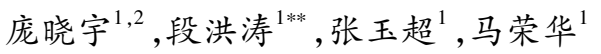 \\ ( 1 : 中国科学院南京地理与湖泊研究所湖泊与环境国家重点实验室,南京 210008) \\ (2:西北大学城市与环境学院,西安 710127)
}

\begin{abstract}
摘 要: 藻蓝蛋白是蓝藻的指示型色素, 目前还没有标准的提取方法, 特别是萃取剂的选择品种较多, 对测量结果影响较 大. 分别以室内培养的铜绿微囊藻和巢湖夏季野生蓝藻为提取对象, 运用液氮反复冻融法破碎蓝藻细胞, 分别以 AsolctinCHAPS 缓冲液 $(A C)$ 、磷酸盐缓冲液 $(\mathrm{PBS})$ 和 Tris-HCl 缓冲液来提取藻蓝蛋白, 通过分光光度法分析提取液的吸收光谱、 藻蓝蛋白浓度以及藻蓝蛋白浓度与叶绿素 $\mathrm{a}$ 浓度的相关性, 比较 3 种缓冲液的提取效果. 结果显示: 3 种缓冲液提取的藻 蓝蛋白提取液在 $620 \mathrm{~nm}$ 处都出现了藻蓝蛋白的特征吸收峰,但 AC 缓冲液和 PBS 缓冲液提取效率明显高于Tris-HCl缓冲 液. 另外,虽然 $\mathrm{AC}$ 缓冲液提取效率最高,但其成本昂贵、配制过程复杂且不易控制、难保存,不适宜大规模地推广应用;而 PBS 缓冲液的提取效率略低于 AC 缓冲液,但其配制方便快捷,更适合于大规模湖泊水质监测的要求,因此推荐 PBS 缓冲 液作为常用的藻蓝蛋白提取液.
\end{abstract}

关键词: 藻蓝蛋白;Asolctin-CHAPS 缓冲液;磷酸盐缓冲液; Tris-HCl 缓冲液;蓝㩰;色素提取;巢湖

\section{Comparison of the extraction methods of phycocyanin pigments in eutrophic lake waters}

\author{
PANG Xiaoyu ${ }^{1,2}$, DUAN Hongtao ${ }^{1}$, ZHANG Yuchao $^{1} \&$ MA Ronghua $^{1}$ \\ ( 1 : State Key Laboratory of Lake Science and Environment, Nanjing Institute of Geography and Limnology, Chinese Academy of \\ Sciences, Nanjing 210008 ,P. R. China) \\ (2: College of Urban and Environmental Sciences, Northwestern University,Xi'an 710127,P. R. China)
}

\begin{abstract}
The paper compares the effects of three methods of phycocyanin extraction buffer and tries to find out which method is the best. Cultured Microcystis aeruginosa and cyanobacteria blooms water samples of Lake Chaohu were used as extract objects. By repeated freezing and thawing method, cyanobacterial cells were broken, and then applied with Asolctin-CHAPS buffer, phosphate buffer and Tris-HCl buffer solution as extractant agent for extracting phycocyanin. Finally, spectrophotometry was used to detect the content of phycocyanin. We analyzed the absorption spectrum of the phycocyanin extract, the concentration of phycocyanin and the relevance between phycocyanin concentration and chlorophyll-a concentration to compare the quality of three methods. Absorption spectra show that all the characteristic absorption peaks of phycocyanin are emerged at $620 \mathrm{~nm}$. Experimental results show that AC buffer and PBS buffer are better than the Tris-HCl buffer in extraction efficiency. In comparison, AC buffer is more expensive and difficult to obtain and save than the other two buffers, which makes it not suitable for large-scale use. So we recommend PBS buffer as the normal buffer which can meet the requirements of large-scale water quality monitoring.

Keywords: Phycocyanin; Asolctin-CHAPS buffer; PBS buffer; Tris-HCl buffer; cyanobacteria; pigment extraction; Lake Chaohu
\end{abstract}

目前我国有 $66 \%$ 以上的湖泊及水库都处于富营养化水平,其中 $22 \%$ 为重富营养化和超富营养化,因此 富营养化成为我国湖泊目前与今后相当长一段时期内的重大水环境问题 ${ }^{[1]}$. 而随着水体的富营养化水平不 断加剧,蓝藻水华频繁暴发,严重威胁着湖泊流域地区的社会经济可持续发展. 由于蓝藻体内含有藻胆蛋

* 国家高技术研究发展计划“863”项目(2014AA06A509)、国家自然科学基金项目 (41171271,41171273,41101316)、 国家水体污染控制与治理科技重大专项项目 (2012ZX07103-005) 和中国科学院南京地理与湖泊研究所“一三五” 战略发展规划项目 (NIGLAS2012135014, NIGLAS2012135010) 联合资助. 2013-08-22 收稿;2013-10-22 收修改 稿. 庞晓宇(1986 ), 男,硕士研究生;E-mail:bzpangxiaoyu@163.com.

** 通信作者; E-mail: htduan@ niglas. ac. cn. 
白, 与其他藻类相比, 其对光的利用有更宽的波长范围, 往往成为水体中的优势种群 ${ }^{[2]}$. 藻胆蛋白主要可分 为藻蓝蛋白 (Phycocyanin, PC) 、藻红蛋白 (Phycoerythrin, PE) 、别藻蓝蛋白 (Allophycocyanins, APC) 和藻红 蓝蛋白 (Phycoerythrocyanin, PEC ${ }^{[3]}$. 藻蓝蛋白 $(\mathrm{PC})$ 又称藻蓝素, 是蓝藻的指示性色素蛋白, 在波长 $620 \mathrm{~nm}$ 附近具有特征吸收峰 ${ }^{[4-6]}$. 在环境监测中, 常以叶绿素 a 浓度作为富营养化湖泊水质监测的重要指标, 但是 叶绿素 a 存在于所有的真核藻类中, 而针对能有效表征蓝澡生物量的 PC 的研究较少 ${ }^{[7]}$.

目前, 藻蓝蛋白的提取与定量方法较多, 且绝大多数的研究都以室内培养的单一藻种为对象 ${ }^{[8-16]}$, 较少 涉及富营养化严重而藻种复杂繁多的湖泊自然水体; 而且多侧重于分析 PC 的浓度, 较少做吸收光谱方面的 分析 ${ }^{[17]}$. 实验室内提取 PC 的一般流程为: 细胞破碎 $\rightarrow$ 分离提取 (粗提取) 一浓度测定.

目前细胞破碎的主要方法有超声波破碎法、反复冻融法、溶胀法、研磨法、化学试剂处理法及高压均质 法等 ${ }^{[8-16,18-24]}$. 如 Bennett 等 ${ }^{[4]}$ 曾用反复冻融法来破碎藻细胞. 林红卫等 ${ }^{[14]}$ 用化学试剂法破坏钝顶螺旋藻细 胞膜提取藻蓝蛋白. 余九九等 ${ }^{[19]}$ 在对螺旋藻藻胆蛋白的提取中, 认为 $\mathrm{CaCl}_{2}$ 低温 $\left(4^{\circ} \mathrm{C}\right)$ 自溶提取效果最好. 张静等 ${ }^{[23]}$ 对比反复冻融法、超声波法、溶胀法、丙酮法的提取效果, 认为反复冻融法提取的藻蓝蛋白浓度优 于其他 3 种方法. 事实上, 细胞破碎方法各有优缺点, 超声波破碎法易产生高温引起 PC 变性, 溶胀法提取周 期较长, 化学试剂法易产生污染等. 由于反复冻融法在整个过程中, 滤膜始终在包有铝箔纸的冻存管中, 可 以做到避免光解、不易污染, 人为干扰最小, 能保证测定的准确性. 由于液氮温度较低, 可达 $-196^{\circ} \mathrm{C}$, 冷冻效 果好、时间短, 因此本文选用液氮反复冻融法作为细胞破碎方法.

在藻蓝蛋白提取的实验中, 缓冲液 (提取剂) 对藻蓝蛋白提取实验的成败也有着较大的影响. 不同的提 取剂有着不同的理化性质, 因此实验结果也有较大差异. 生物缓冲液的作用就是保证提取过程中藻蓝蛋白 提取液酸碱性的相对稳定, 起到缓冲作用, 在蛋白质的提取中, 缓冲液的应用较为常见. 目前常用的缓冲液 为磷酸盐缓冲液 $(\mathrm{PBS})^{[4,9-10,19]}$ 、Tris- $\mathrm{HCl}$ 缓冲液 ${ }^{[11]}$ 以及 Acolectin-CHAPS 缓冲液 ${ }^{[22,25-26]}$. 如 Bennett 等 ${ }^{[4]}$ 早在 1973 年便运用 PBS 提取蓝藻单歧藻中的藻胆蛋白. 国内张薇君等 ${ }^{[9-10,19,24]}$ 均使用 PBS 来提取藻蓝蛋白. 张静 等 ${ }^{[23]}$ 在提取太湖水体蓝藻的实验中, 认为 PBS 缓冲液的浓度在 $0.01 \sim 0.20 \mathrm{~mol} / \mathrm{L}$ 范围内, 藻蓝蛋白的提取 效果变化不大. 而张熙颖等 ${ }^{[26]}$ 在研究钝顶螺旋藻的藻胆体在不同缓冲液中的稳定性实验中, 认为在 $1 \mathrm{~mol} / \mathrm{L}$ 的 PBS 中, 藻胆体的稳定性强, 而在低浓度 $(<0.6 \mathrm{~mol} / \mathrm{L}) \mathrm{PBS}$ 中, 藻胆体易解离, 解离速度随 PBS 浓度的降 低而加快; 同时 CHAPS (表面活性剂) 即便在高离子强度条件下也可以使藻胆体解离. Viskari 等 ${ }^{[22]}$ 将 Acolectin (大豆磷脂) 溶于 CHAPS 中, 制成 Acolectin-CHAPS 缓冲液来提取聚球藻 CCMP833 中的藻胆蛋白, 提取效率大于 $85 \%$. 李邵蓉等 ${ }^{[11]}$ 采用 Tris- $\mathrm{HCl}$ 缓冲液从 Rhodosorus marinus 中提取了藻红蛋白, 并测定了其 聚合体的分子量及光谱. Zimba ${ }^{[25]}$ 对比了 Acolectin-CHAPS 缓冲液和 PBS 的提取效果, 认为 Acolectin-CHAPS 缓冲液的萃取能力更强,但没有指出该缓冲液自身的性质(有颜色)对实验结果的影响.

在确定了细胞破碎方法的基础上, 还要选取最合适的提取剂, 才能确定适用于湖泊水环境监测要求的 实验条件和方法. 本文以室内培养的铜绿微囊藻 (Microcystic aeruginosa) 和巢湖水体捞取的水华蓝藻 (铜绿 微囊藻主导) 为提取对象, 采用液氮低温 $\left(-196^{\circ} \mathrm{C}\right)$ 反复冻融法来破碎细胞, 分别用上述 3 种缓冲液来提取 铜绿微囊藻和野外水华蓝藻中的藻蓝蛋白. 以测定的藻蓝蛋白的浓度和吸收光谱为基础, 再将测定的藻蓝 蛋白浓度与叶绿素 a 浓度之间的相关性作为评价因子之一, 对 3 种提取剂进行分析评价, 探求最适于蓝藻水 华监测大规模实验的藻蓝素提取的标准测量方法, 为巢湖水体蓝藻水华监测提供基础支撑.

\section{1 材料与方法}

实验以在巢湖实地采集的水样以及室内培养的铜绿微囊藻为藻蓝蛋白 $(\mathrm{PC})$ 的提取对象, 室内培养藻种 由湖泊与环境国家重点实验室提供.

\section{1 样品采集与滤膜准备}

于 2013 年 6 月 14 日采集巢湖姥山岛以西湖区表层 $30 \mathrm{~cm}$ 处的水样, 共采集 4 个样点(图 1), 分别记作 C-1、C-2、C-3、C-4. 采样期间风速为 $1.9 \sim 2.7 \mathrm{~m} / \mathrm{s}$, 气象条件较好; 采样区水面漂浮着大量的蓝藻颗粒, 形成 了蓝藻水华. 采集的水样立即在真空原抽气条件下用孔径为 $1.2 \mu \mathrm{m}$ 的 Whatman GF/C 玻璃纤维滤膜过滤, 每种提取方法平行采集相同体积的水样, 不同样点水质状况各异, 所以过滤体积不同. 抽滤完毕后, 立即将 
吸干的滤膜折叠包裹于铝簿纸内, 并置于 $-20^{\circ} \mathrm{C}$ 冰箱冷冻保存.

室内藻种实验共设置 9 个浓度, 首先 从摚拌均匀的藻液中分别取 $10 、 25 、 50 、 75$ 、 $100 、 125 、 150 、 175 、 200 \mathrm{ml}$ 藻液, 均用纯水稀 释至 $2 \mathrm{~L}$, 依次标记为 $\mathrm{M}-1 、 \mathrm{M}-2 、 \mathrm{M}-3 、 \mathrm{M}-4$ 、 M-5、M-6、M-7、M-8、M-9. 搅拌均匀后, 每个 样点均过滤 $200 \mathrm{ml}$ 的水样, 该滤膜与上述 巢湖水样的滤膜保存方法相同. 另外, 巢湖 野外水样与室内实验样品都设置 3 个平行 样, 最后结果取其平均值.

\section{2 缓冲液的配制}

3 种缓冲液分别为 Asolectin-CHAPS 缓

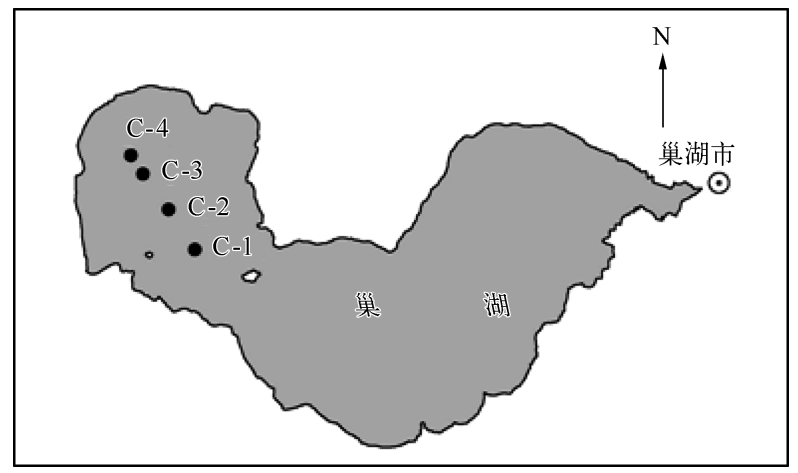

图 1 巢湖采样点分布示意图

Fig. 1 Distribution of sampling sites in Lake Chaohu 冲液 ( 以下简称 $\mathrm{AC}$ ) 、磷酸盐缓冲液 $(\mathrm{PBS}$ ) 以及 Tris-HCl 缓冲液,按照下述方法配制 3 种缓冲液.

$\mathrm{AC}$ 缓冲液: 配制 $\mathrm{AC}$ 缓冲液共分 3 步进行. 第一步,将 Asolectin 溶解在少量的乙醚中, 在氮吹仪作用下 吹至瓶底出现一层厚厚的黄色膜为止; 第二步,将 $\operatorname{CHAPS}$ (3-[ (3-胆固醇氨丙基)二甲基氨基]-1-丙磺酸)溶 于灭菌的去离子水中,浓度为 3\% (W/V) ; 第三步,将第一步中干燥的 Asolectin 溶于第二步中配好的 CHAPS 溶液中, 浓度为 $0.3 \%(\mathrm{~W} / \mathrm{V}) . \mathrm{AC}$ 缓冲液 $\mathrm{pH}$ 为 $6.7^{[22,25]}$.

$0.05 \mathrm{~mol} / \mathrm{L}$ 的 PBS 缓冲液: 将 $0.05 \mathrm{~mol} / \mathrm{L}$ 的磷酸二氢钾溶液和 $0.05 \mathrm{~mol} / \mathrm{L}$ 磷酸氢二钾以体积比 $45: 55$ 混合, 溶液 $\mathrm{pH}$ 为 7.0 .

Tris- $\mathrm{HCl}$ 缓冲液: 将 Tris-base 干粉溶于灭菌的去离子水中, 浓度为 $0.05 \mathrm{~mol} / \mathrm{L}(3 \mathrm{~g} / \mathrm{L})$, 用浓盐酸调节 $\mathrm{pH}$ 至 7.0.

\section{3 藻蓝蛋白的提取}

本文分别采用上述 3 种缓冲液提取藻蓝蛋白,流程为: 将滤膜放人冻存管中, 同时加人缓冲液, 于液氮 罐中冷冻 $1 \mathrm{~h}$, 然后取出样品在室温避光条件下溶化,此过程重复 3 次. 然后在 $-4^{\circ} \mathrm{C}$ 黑暗条件下提取 $15 \mathrm{~h}$. 解 冻的样品在 $4^{\circ} \mathrm{C} 、 14000$ 转 $/ \mathrm{min}$ 的条件下离心 $15 \mathrm{~min}$, 取上清液作为待测液. 由于藻蓝蛋白见光易分解 ${ }^{[16]}$, 所 以整个实验流程在避光环境下进行.

\section{4 藻蓝蛋白浓度的测定}

待测液使用岛津 UV-2600 紫外可见光分光光度计测量 615 、652 和 $750 \mathrm{~nm}$ 处的吸光度. 分光光度计光谱 扫描波长为 $450 \sim 750 \mathrm{~nm}$, 分辨率为 $1 \mathrm{~nm}$.

根据 Bennett 等 ${ }^{[4]}$ 的公式计算 PC 浓度：

$$
C_{\mathrm{PC}}=1000\left(\frac{A_{615}-0.474 A_{652}}{5.34}\right) \frac{V_{1}}{V_{2}} \cdot L
$$

对 Bennett 等的公式改进为:

$$
C_{\mathrm{PC}}=1000\left[\frac{\left(A_{615}-A_{750}\right)-0.474\left(A_{652}-A_{750}\right)}{5.34}\right] \frac{V_{1}}{V_{2}} \cdot L
$$

式中, $C_{\mathrm{PC}}$ 为藻蓝蛋白的浓度 $(\mu \mathrm{g} / \mathrm{L}), A_{615} 、 A_{652}$ 分别为 $615 、 652 \mathrm{~nm}$ 处的吸光度值, $V_{1}$ 为待测液的定容体积 $(\mathrm{ml}), V_{2}$ 为水样的过滤体积 $(\mathrm{L}), L$ 为比色血光程 $(\mathrm{cm})$. 改进公式主要是基于提高计算精确性的考虑,由于待 测液采用离心法 (物理分离方法) 分离制备, 分离不够完全, 为消除杂质影响, 提高测量的精确度, 根据文献 [28] 中介绍的叶绿素 $\mathrm{a}$ 浓度测定公式,用 $A_{615}$ 和 $A_{652}$ 来减去 $A_{750}$ 作为已校正过的吸光度值,然后再进行计算.

\section{5 叶绿素 $\mathrm{a}$ 浓度的测定}

蓝藻中含有叶绿素、藻胆色素等多种色素, 在水华蓝藻监测中, 叶绿素和藻蓝素都可作为衡量蓝藻生物 
量的指标 ${ }^{[29]}$. 在蓝藻数量占绝对优势的情况下, 叶绿素和藻蓝素的含量应具有显著的正相关性. 由于叶绿素 测定方法较为成熟, 因此本文在采用 3 种缓冲液提取测定每个样点藻蓝蛋白含量的同时,均运用丙酮法 ${ }^{[27]}$ 提取并测定其平行样的叶绿素 a 浓度, 并对藻蓝蛋白浓度与叶绿素 a 浓度做相关性分析. 具体做法为: 将反 复冻融后的滤膜加人到 $90 \%$ 的丙酮溶液中浸泡 $12 \sim 15 \mathrm{~h}$, 然后在 7000 转/ $\mathrm{min}$ 的转速下离心 $10 \mathrm{~min}$, 最后取 上清液作为叶绿素 $\mathrm{a}$ 的待测液. 计算公式 ${ }^{[28]}$ 为:

$$
C_{\text {Chl. a }}=\frac{\left[1 1 . 6 4 \left(A_{663}-A_{750}-2.16\left(A_{645}-A_{750}\right)+0.1\left(A_{630}-A_{750}\right] V_{1}\right.\right.}{V_{2} \cdot L}
$$

式中, $C_{\text {Chl. a }}$ 为叶绿素 $\mathrm{a}$ 浓度 $(\mu \mathrm{g} / \mathrm{L}), A_{630} 、 A_{645} 、 A_{663} 、 A_{750}$ 分别为 $630 、 645 、 663 、 750 \mathrm{~nm}$ 处的吸光度值, $V_{1}$ 为提取 液的体积 $(\mathrm{ml}), V_{2}$ 为水样的过滤体积 $(\mathrm{L})$.

\section{2 结果}

\section{1 不同缓冲液提取的藻蓝蛋白吸收光谱}

在扫描波长为 $450 \sim 750 \mathrm{~nm}$ 范围内, 提取对象无论是室内藻种还是巢湖水样, 3 种不同缓冲液提取的藻 蓝蛋白吸收光谱在 $620 \mathrm{~nm}$ 波长处均出现主吸收峰. 其中, AC 法提取液的吸收光谱峰高最高, PBS 法的峰高 相对 AC 法略低一些, Tris-HCl 法的峰高最低. 室内藻种 3 种缓冲液的藻蓝蛋白吸收光谱在 $620 \mathrm{~nm}$ 附近的吸 收峰峰高之间的差距较巢湖水样小. 此外, AC 法所有样点和 Tris 法的个别样点在 $670 \mathrm{~nm}$ 附近均出现次吸收 峰, 且 AC 法 $667 \mathrm{~nm}$ 处的吸收峰明显. 室内藻种和巢湖水样的 AC 法吸收光谱出现的双峰也存在显著差异, 室内藻种双峰峰高有明显差异, $620 \mathrm{~nm}$ 处为主吸收峰, $670 \mathrm{~nm}$ 为次吸收峰, 而巢湖水样中双峰并无主次之 分. 另外, $\mathrm{AC}$ 法的藻蓝蛋白吸收光谱曲线在 $700 \sim 750 \mathrm{~nm}$ 处出现负值, 这主要受参比溶液本身有颜色的影 响. PBS 法提取液的藻蓝蛋白特征吸收光谱曲线较稳定, 700 $800 \mathrm{~nm}$ 处吸光度值接近于 0 , 说明受杂质影响 较小, 提取液纯度相对较高. Tris-HCl 法提取液的吸收光谱曲线显得较为杂乱, 700 800 nm 处的谱线明显高 于基线很多,说明提取液中杂质较多(图 2).
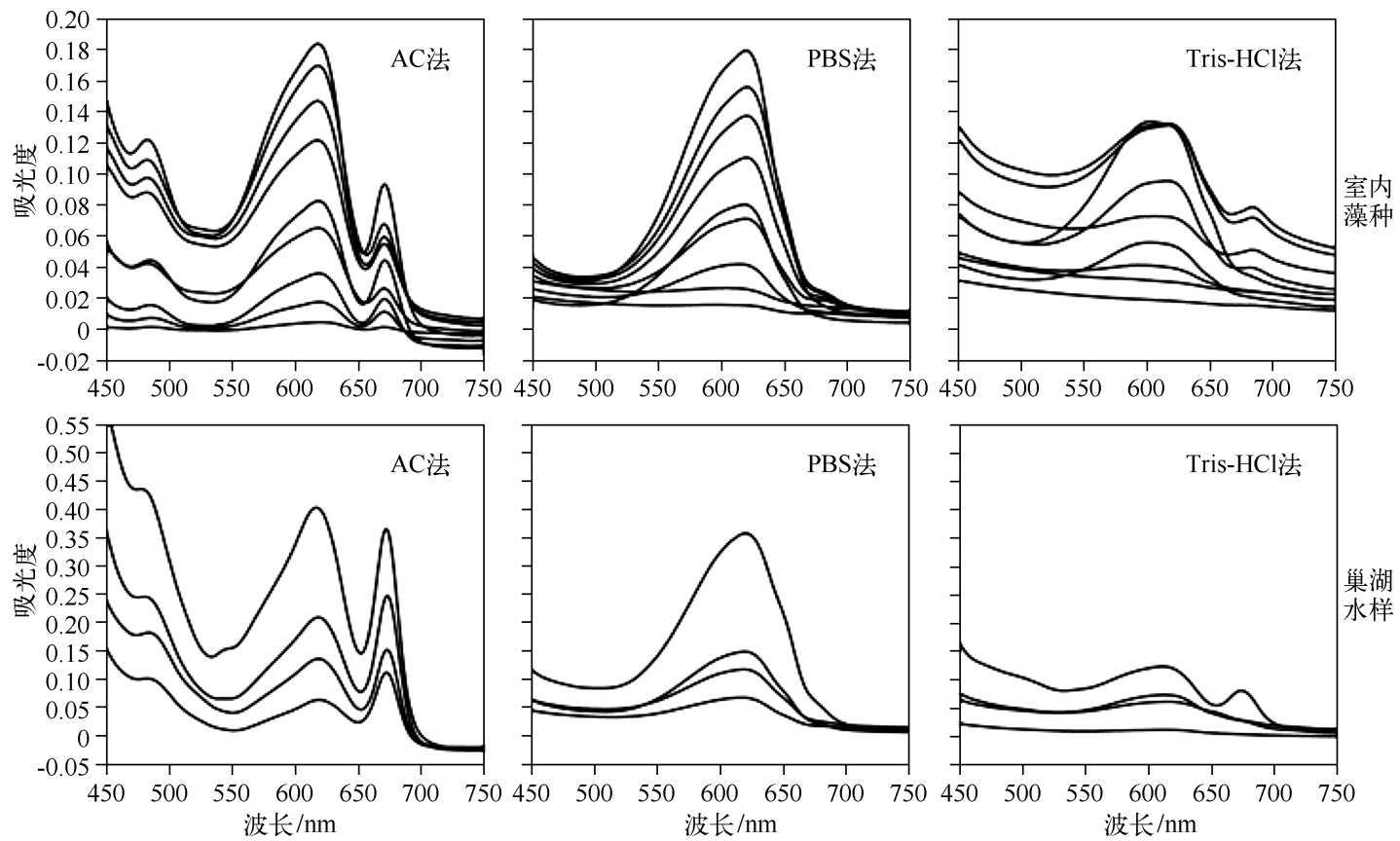

图 2 不同缓冲液提取的藻蓝蛋白吸收光谱

Fig. 2 Absorption spectrums of phycocyanin extracted by different buffer solutions 


\section{2 不同缓冲液提取的藻蓝蛋白浓度}

根据测定的上清液的吸光度值, 代人到改进后的公式 (2), 分别计算室内藻种和巢湖水样不同缓冲液提 取的藻蓝蛋白浓度. 结果表明, 3 种缓冲液提取的藻蓝蛋白浓度有明显差异, AC 法提取的 PC 浓度最高, PBS 法次之, Tris-HCl 法最低, PC 浓度的高低和吸收光谱的特征吸收峰的高低相对应. 而且在低浓度水样中, 采 用 AC 法和 PBS 法提取的 PC 浓度差异不大,随着水样浓度的提高, AC 法和 PBS 法提取的 PC 浓度明显高于 Tris- $\mathrm{HCl}$ 法. 不同缓冲液提取的藻蓝蛋白浓度比较结果见图 3(浓度值为 3 个平行样的均值). 3 种缓冲液提 取的藻蓝蛋白浓度变异系数的均值均小于 0.10 , 说明实验稳定性较好 (表 1 ).

表 1 不同样品中藻蓝蛋白浓度的变异系数

Tab. 1 Variation coefficient of phycocyanin concentration in different samples

\begin{tabular}{cccccccccccccc}
\hline 缓冲液 & M-1 & M-2 & M-3 & M-4 & M-5 & M-6 & M-7 & M-8 & M-9 & C-1 & C-2 & C-3 & C-4 \\
\hline AC & 0.01 & 0.06 & 0.01 & 0.02 & 0.25 & 0.02 & 0.03 & 0.02 & 0.01 & 0.12 & 0.03 & 0.04 & 0.03 \\
PBS & 0.18 & 0.19 & 0.01 & 0.01 & 0.08 & 0.02 & 0.01 & 0.03 & 0.01 & 0.03 & 0.06 & 0.06 & 0.05 \\
Tris-HCl & 0.12 & 0.15 & 0.07 & 0.05 & 0.01 & 0.02 & 0.00 & 0.02 & 0.03 & 0.12 & 0.04 & 0.09 & 0.06 \\
\hline
\end{tabular}

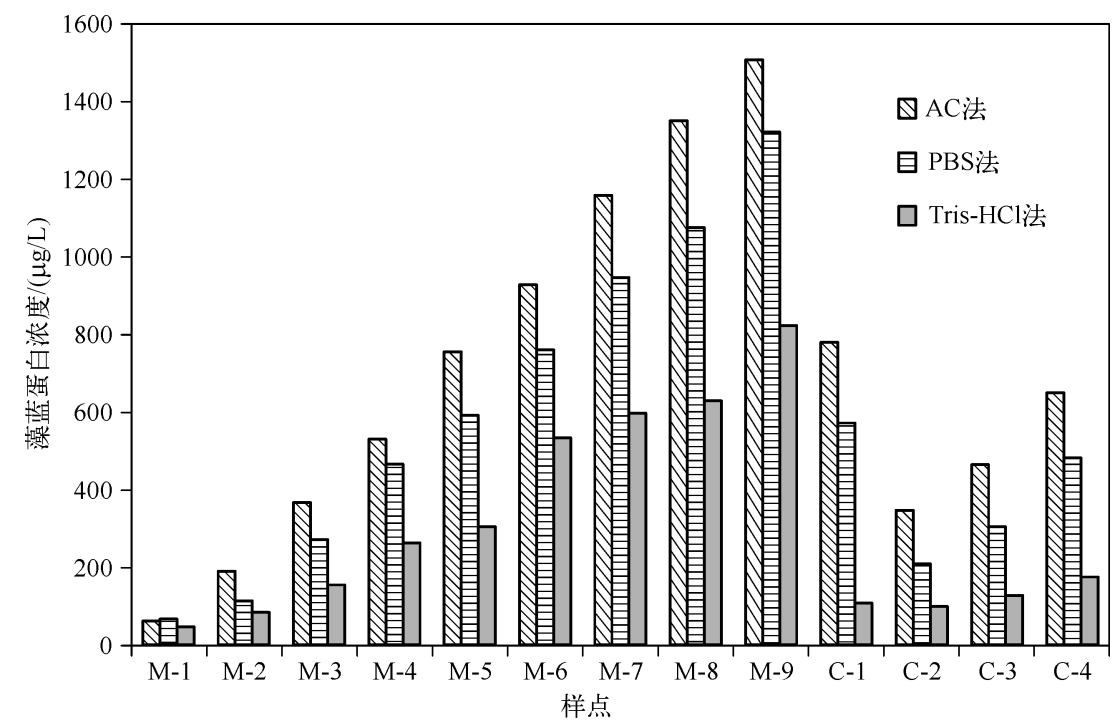

图 3 不同缓冲液提取的藻蓝蛋白浓度对比 (为便于作图比较, C-2、C-3、C-4 取其浓度值的 1/10)

Fig. 3 Comparison of the phycocyanin concentration on different buffer solutions

\section{3 不同缓冲液提取的 PC 浓度与叶绿素 $\mathrm{a}$ 浓度的相关性分析}

分别将 3 种缓冲液提取的藻蓝蛋白浓度与对应点的叶绿素 a 浓度做相关性分析 (图 4), 结果表明二者 呈良好的线性关系, 拟合度 $R^{2}$ 均在 0.9 以上. 其中, 室内藻种 AC 法、PBS 法、Tris-HCl 法提取的 PC 浓度与 Chl. a 浓度均呈极显著相关 $\left(R_{\mathrm{AC}}^{2}=0.9953 、 R_{\mathrm{PBS}}^{2}=0.9867 、 R_{\mathrm{Tris}-\mathrm{HCl}}^{2}=0.9692 ; P<0.01\right)$, 巢湖水样 $\mathrm{AC}$ 法、PBS 法、Tris-HCl 法提取的 PC 浓度与 Chl. a 浓度均呈显著相关 $\left(R_{\mathrm{AC}}^{2}=0.9694 、 R_{\mathrm{PBS}}^{2}=0.9690 、 R_{\mathrm{Tris}-\mathrm{HCl}}^{2}=0.8736\right.$; $P<0.05) .3$ 种缓冲液中, AC 法提取的 PC 浓度与 Chl. a 浓度的相关性最高; 需要注意的是, 室内藻种和巢湖 水样在 PC 浓度与 Chl. a 含量的相关性上表现出差异, 这是由于巢湖野外水体中可能含有不同藻类.

\section{3 讨论}

\section{1 吸收光谱对比分析}

吸收光谱可以反映出某种物质对不同波长的辐射, 可以对被测量物质进行定性或者定量 ${ }^{[30]}$. 以叶绿素 


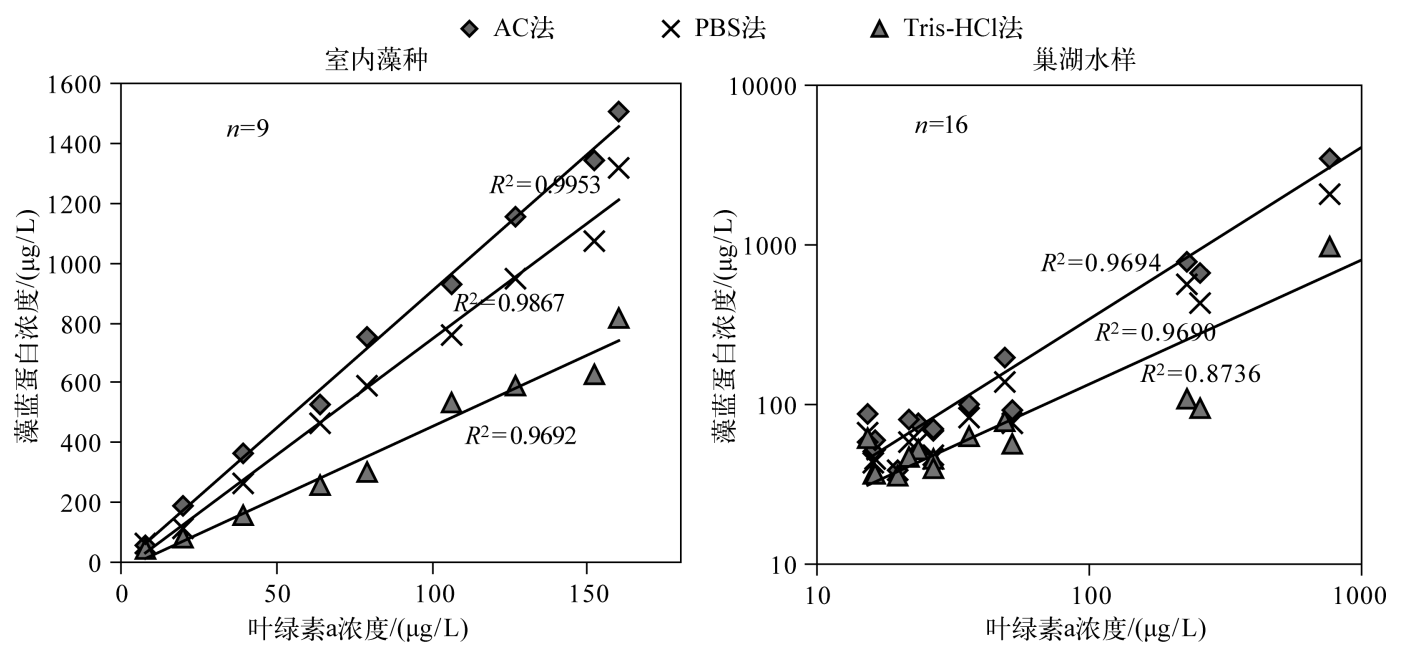

图 4 叶绿素 a 浓度与不同缓冲液提取的 PC 浓度的线性关系

Fig. 4 Scattergram of chlorophyll-a concentrations versus phycocyanin concentrations extracted by different buffer solutions

为例, 其吸收峰在红光和蓝光处 (因此叶绿素可以反射绿光). 藻蓝蛋白的特征吸收峰在 $620 \mathrm{~nm}$ 附近, 本文 用 3 种缓冲液提取的室内培养铜绿微囊藻和巢湖水样的 PC 提取液均在 $620 \mathrm{~nm}$ 附近出现特征吸收峰. $\mathrm{AC}$ 法在 $620 \mathrm{~nm}$ 附近的峰高最高, 略高于 PBS 法, Tris- $\mathrm{HCl}$ 法峰高最低且明显低于前 2 种方法.

$\mathrm{AC}$ 法提取的 PC 提取液的吸收光谱均出现双吸收峰, 对于室内藻种, 双峰有主次之分, $620 \mathrm{~nm}$ 处为主吸 收峰, $670 \mathrm{~nm}$ 处为副吸收峰. 主要原因是 CHAPS 为两性增溶剂 (表面活性剂), 它含有疏水基(亲油基)和亲 水基两部分, 分子两端为结构和性能相反的基团, 以化学键相连接. 由于其不对称的极性结构, 具有既亲水 又亲油的双亲性质,因此也被称为“双亲分子” ${ }^{[31]}$. 因此,在使用 AC 缓冲液提取 PC 的时候,也会有脂溶性的 色素溶人, $670 \mathrm{~nm}$ 处的吸收峰主要是由于提取液中溶人了脂溶性的色素 ( 叶绿素 a ${ }^{[25]}$ 所造成的. 此外, 藻蓝 蛋白的提取液为粗提液, 还可能含有别藻蓝蛋白、叶绿素蛋白复合体以及少量的细胞碎片等杂质 ${ }^{[17]}$, 它们的 存在也会对 PC 提取液的光谱产生影响. 另外 AC 法的吸收光谱在 $700 \sim 750 \mathrm{~nm}$ 处的吸收谱线为负值, 原因 是 $\mathrm{AC}$ 缓冲液为浅黄色澄明的液体, 缓冲液本身有颜色, 由于测量时作为参比的 $\mathrm{AC}$ 缓冲液是有颜色的, 而 在藻蓝蛋白浓度较低的提取液中, 由于藻蓝蛋白的浓度很低, 而 $\mathrm{AC}$ 缓冲液本身的颜色对待测液的影响较 大, 造成待测液的吸光度在 $700 \sim 800 \mathrm{~nm}$ (纯水吸收峰的范围) ${ }^{[32]}$ 处的吸光度的值为 “不合理” 的负值.

PBS 法吸收光谱的特征峰峰高与 AC 法的相比略低一些, 但是峰高的差别不大. 且 PBS 法的吸收光谱与 张静 ${ }^{[17]}$ 等做出的 PC 标样的吸收光谱基本一致. PBS 法的吸收光谱只在 $620 \mathrm{~nm}$ 处出现特征峰, 证明蓝藻细 胞破碎完全, 其他色素的溶人较少, 提取效果较好. PBS 配制较为方便快捷, 以往众多的研究 ${ }^{[4,9-10,15,19]}$ 表明, PBS 是目前最常用的 PC 提取液.

Tris-HCl 法的 PC 提取液的吸收光谱同 AC 法和 PBS 法的吸收光谱有明显差异, PC 的特征吸收峰峰高 最低, 且相对前 2 种缓冲液峰高有着明显的降低. 另外, 从吸收光谱图可以看出, 在 $670 \mathrm{~nm}$ 处出现了微弱的 次吸收峰,700 $800 \mathrm{~nm}$ 处谱线明显高于基线 (图 2), 受杂质影响较大, 提取效果不够稳定.

\section{2 藻蓝蛋白提取液浓度对比分析}

相同的水样, 3 种缓冲液提取的 PC 浓度也有明显的差异, AC 法提取的 PC 浓度最高, PBS 法稍次之, Tris-HCl 法提取的 PC 浓度最低, 且明显低于前 2 种方法 (图 3) ; 这与提取液的吸收光谱也相一致, 特征峰越 高相应的 PC 浓度也越高. 室内藻种 AC 法、PBS 法和 Tris-HCl 法提取的 PC 平均浓度分别为 757.596、 620.832 和 $378.241 \mu \mathrm{g} / \mathrm{L}$. 巢湖水华蓝藻中 AC 法、PBS 法和 Tris-HCl 法提取的 PC 平均浓度分别为 3827.22 、 2615.61 和 1015.05 $\mu \mathrm{g} / \mathrm{L}$. 因为 AC 缓冲液中的 CHAPS 为两性增溶剂, 其溶液中有多层次、多种类的胶束存 
在,使其具有增溶性 ${ }^{[33]}$, 因此其提取的 PC 浓度最高. 实验证明, AC 法提取的 PC 浓度比 PBS 法高 $18 \%$, 比 Tris- $\mathrm{HCl}$ 法高 $51 \%$. 从平行样浓度的变异系数来看, 3 种方法下平行样的变异系数都很低, 最大值为 0.25 , 最 小值为 0.01 ,均值为 0.05 (表 1 ). 这说明本实验测量的误差较小.

\section{3 藻蓝蛋白浓度与叶绿素 a 浓度的关系}

由于叶绿素 $\mathrm{a}$ 存在于所有的真核藻类中, 而藻蓝蛋白只存在于蓝藻中,所以分析野外水体中藻蓝蛋白 与叶绿素 a 浓度相关性的前提是, 水样中蓝藻生物量必须比例一致或占绝对优势, 否则分析将失去意义. 本 实验中, 采样点为蓝藻水华暴发区域, 蓝藻为绝对优势种群. 另外, 由于室内纯藻和巢湖水样在实验结果上 高度的一致性, 也证明了所采水样中蓝藻占绝对优势. 但是野外水体水质复杂, 虽然蓝藻的生物量占绝对优 势, 但是巢湖水样中藻蓝蛋白浓度与叶绿素 a 浓度的相关性略低于室内纯藻种, 由此可说明此时的野外水 体中也存在极少量其他藻类. 由上述数据可知, 蓝藻中藻蓝蛋白和叶绿素的含量具有极为显著的相关性. 3 种缓冲液提取的藻蓝蛋白浓度与丙酮法提取的叶绿素 a 浓度之间均表现出显著相关,但是 $\mathrm{AC}$ 法的相关性 最高, 其次为 PBS 法, Tris-HCl 法最低(图 4).

\section{4 结论}

综上所述, $\mathrm{AC}$ 缓冲液的提取效率最好, 但是该缓冲液成本较高, 配制过程较复杂且该缓冲液超过 $12 \mathrm{~h}$ 便不能使用, 不宜保存, 不适于大批量样品的提取测定. PBS 缓冲液提取的藻蓝蛋白浓度低于 AC 缓冲液, 其 优势在于配制较为方便快捷、成本较低、适合大批量样品的提取测定. Tris-HCl 缓冲液提取率最低, 且从光谱 分析结果来看,其提取效果不够稳定,不推荐该缓冲液作为藻蓝蛋白的提取剂. 总之,不同的实验目的和实 验对象, 对不同的缓冲液有不同的要求, 在湖泊水环境监测中, 由于 $\mathrm{AC}$ 缓冲液不适于大规模的推广应用, 本 文推荐采用 PBS 缓冲液作为藻蓝蛋白提取剂.

致谢: 感谢中国科学院南京地理与湖泊研究所“湖泊一流域科学数据共享平台”提供数据. 藻蓝蛋白提取实验 得到了姜广甲、王长风、齐琳、易梅森、黄佳慧、马孟臬、刘菲菲、张静等的帮助,在此表示感谢.

\section{5 参考文献}

[ 1 ] 黄渏平. 太湖水环境及其污染控制. 北京:科学出版社,2001.

[ 2 ] 秦伯强,王小冬,汤祥明等. 太湖富营养化与蓝藻水华引起的饮用水危机一一原因与对策. 地球科学进展, 2007,22 (9) : 896-906.

[ 3 ] 王广策, 邓 田,曾呈奎. 藻胆蛋白的研究概况 ( I ) 一一藻胆蛋白的种类与组成. 海洋科学, 2000,24(2): 22-25.

[ 4 ] Bennett A, Bogorad L. Complementary chromatic adaptation in a filamentous blue-green alga. Journal of Cell Biology, $1973, \mathbf{5 8}(2): 419-435$.

[ 5 ] Soni B, Kalavadia B, Trivedi U et al. Extraction, purification and characterization of phycocyanin from Oscillatoria quadripunctulata-Isolated from the rocky shores of Bet-Dwarka, Gujarat, India. Process Biochemistry, 2006, 41 (9) : 2017-2023.

[ 6 ] Jupp DL, Kirk JT, Harris GP. Detection, identification and mapping of cyanobacteria-using remote sensing to measure the optical quality of turbid inland waters. Marine and Freshwater Research, 1994, 45(5) : 801-828.

[ 7 ] 金经纬,段洪涛,赵晨露等. 湖泊藻类水体浮游植物色素遥感反演模型. 红外与毫米波学报,2012,31(2): 132-136.

[8] 汤朝晖,蒋加伦. 针顶螺旋藻藻胆蛋白的提取及其特征初报. 东海海洋,1993,11(4) : 49-54.

[ 9 ] 张薇君,郝纯彦.出口螺旋藻粉中藻胆蛋白测定方法的研究. 光谱仪器与分析, 1999, (3): 8-11.

[10］彭卫民,商树田,刘国琴等. 针顶螺旋藻 (Sp. -D ) 藻胆蛋白的提取. 食品科学, 1999,20(6) : 48-49.

[11] 李邵蓉,林惠民. Rhodosorus marinus 中藻红蛋白的纯化及其性质的研究. 水生生物学报, 1996,20(3): 257-264.

[12] 张成武, 曾昭琪,张媛贞. 钝顶螺旋藻藻胆蛋白的分离、纯化及其理化特性. 天然产物研究与开发, 1996,8 (2): 29-34.

[13］叶海辉,何秀芬,王秀兰.螺旋藻的破碎及藻蓝色素的提取. 华南热带农业大学学报,2001,7(3): 24-30.

[14］林红卫,伍正清,黄文榜等. 钝顶螺旋藻中藻蓝蛋白的提取新工艺. 广西化工, 1997,26(4) : 7-9.

[15] 邹 宁,孙东红,焦爱霞等. 鱼腥藻藻蓝蛋白的提取. 水产养殖, 2005,26(1): 5-7.

[16] 张以芳, 刘旭川, 李琦华. 螺旋藻藻蓝蛋白提取及稳定性试验. 云南大学学报: 自然科学版, 1999,21(3):66-68. 
[17] 张 静, 韦玉春, 王国祥等. 太湖蓝藻水样中藻蓝蛋白提取方法比较. 湖泊科学, 2013,25(2): 283-288.

[18] 朱 劼, 董文杰, 刘 佳. 超声波协同等电点沉淀法提取螺旋藻藻胆蛋白工艺的优化. 食品科学, 2010,31(10): 146-150.

[19］余九九, 李宽钰, 吴庆余. 螺旋藻的藻胆蛋白提取及稳定性研究. 海洋通报, 1997,16(4) : 26-28.

[20] 王 勇, 钱凯先, 董 强. 高纯度藻蓝蛋白分离纯化及光谱特性研究. 生物化学与生物物理进展, 1999, 26 (5): $457-460$.

[21] 梁文裕. 普通念珠藻 (Nostoc commune Vauch. ) 藻蓝蛋白的提取. 安徽农业科学, 2008,36(1) : 113-115.

[22] Viskari PJ, Colyer CL. Rapid extraction of phycobiliproteins from cultured cyanobacteria samples. Analytical Biochemistry, $2003, \mathbf{3 1 9}(2): 263-271$.

[23] 张 静, 韦玉春, 王国祥等. 实验条件对太湖水体中藻蓝蛋白提取结果的影响. 环境科学与技术, 2012,35(10): 1-5.

[24] 李 冰,张学成,高美华等. 钝顶螺旋藻藻蓝蛋白提取纯化新工艺. 海洋科学, 2007,31(8): 48-52.

[25] Zimba PV. An improved phycobilin extraction method. Harmful Algae, 2012, 17 : 35-39.

[26] 张熙颖, 刘鲁宁, 陈秀兰等. 苂光光谱研究两性表面活性剂 CHAPS 对钝顶螺旋藻藻胆体的解离作用. 光谱学与光 谱分析,2004,24(10): 1224-1226.

[27] 中华人民共和国水利部. 中华人民共和国水利行业标准一一水质叶绿素的测定分光光度法 SL 88-2012. 北京, 2012: 2012-07-31.

[28］国家环境保护局《水和废水监测分析方法》编委会. 水和废水监测分析方法. 北京: 中国环境科学出版社,1997.

[29] Zimba PV, Gitelson A. Remote estimation of chlorophyll concentration in hyper-eutrophic aquatic systems: Model tuning and accuracy optimization. Aquaculture, 2006, 256 (1) : 272-286.

[30] 胡 坪, 朱明华. 仪器分析. 北京:高等教育出版社, 2008 .

[31］赵振国,肖进新. 表面活性剂应用原理. 北京: 化学工业出版社,2003.

[32] Smith RC, Baker KS. Optical properties of the clearest natural waters (200-800 nm). Applied Optics, 1981, 20(2): $177-184$.

[33] 秦显国. 两性增溶剂 CHAPS 聚集性质及其与 Triton X-100 相互作用的 NMR 研究 [学位论文]. 武汉: 华中科技大 学, 2011 . 